\title{
Why Flip the Medical Resident \\ Classroom? A Pilot Study in Singapore
}

\section{Maleena Suppiah Cavert}

\section{Pre-meeting I}

Students assimilate and process new information via video lectures and readings
Provide students with unlimited access to content-rich learning objects — students can make their own decisions about which aspects to focus on, to balance their limited time for study and the vast amount of knowledge available

\section{Start of Class}

Quizzes to ensure and assess initial encounter with new material before class

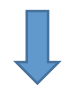

\section{In-Class}

Application exercises, generally requiring student collaboration

M. S. Cavert ( $\square)$

National University Health Systems, Singapore, Singapore

e-mail: maleena_suppiah@nuhs.edu.sg

Serious games for reinforcement of learning, to enhance patient safety skills and overall quality improvement
Active learning through case studies, inquiry-based laboratories, handling of models, role-playing or basic surgical skills like suturing

Groups with few students for greater engagement per student

Case-based and skill-based learning, including problem-solving through application of new knowledge

Z. Walker et al. (eds.), Flipped Classrooms with Diverse Learners, 


\section{Introduction}

Education in healthcare is both exciting and challenging. The healthcare landscape is complex, with integrated and interconnected healthcare systems. Highly specialized care is to be delivered to a growing and increasingly diverse patient population (Prober \& Khan, 2013). Practice-based relevance of instruction is paramount (Simpson \& Richards, 2015). Problem-solving skills in clinical as well as managerial domains need to be honed. Because of the complexity and necessity for continuum of care (acute, step-down and community care), healthcare professionals need to function as efficient and collaborative teams (Hawks, 2014). The quality of instruction that healthcare professionals receive also has to commensurate with the ever-increasing scope and depth of practice (Berwick \& Finkelstein, 2010).

Part of the reason there is a deficit of healthcare professionals in the workforce is due to demographic changes; an ever-increasing proportion of our population consists of the elderly, especially in developed countries. Another need for additional healthcare specialists is because of the alarming rise in the rate of obesity as well as that of non-communicable chronic diseases such as type 2 diabetes, hypertension, hyperlipidemia, stroke, heart disease, some cancers, certain respiratory conditions, sleep disorders, and depression. Our priority is to train work-ready individuals who can help alleviate the shortage of manpower in geriatric care, to manage the burden of disease and to preserve health.

In response to the need for safe and qualified professionals, there are many instructional strategies available in the clinical setting: simulation, standardized patients (trained actors) for clinical and communication skills, role-playing, bedside teaching in ward rounds, small-group tutorials and lectures or traditional didactic learning. The use of technology in healthcare delivery is obvious-diagnostic imaging, electronic health record systems, workflow and work processes software, monitoring, interventional procedures, robot-assisted surgery, to name a few. However, the use of technology as a learning tool in clinical clerkships, e.g., e-learning, has only been prevalent in the last decade (Ruiz, Mintzer, \& Leipzig, 2006). I will focus on one aspect of employing technology for clinical instructionthe flipped classroom model, also known as the inverted classroom model.

Flipping the classroom is enabled by technology. It encompasses the basic transmission of information asynchronously (often online) so that learning in class or on the ground (in work-based settings) is as contextually relevant as possible. Educators who champion the flipped methodology tout its unique marrying of behaviorist (Skinner, 1974) and constructivist ideologies, which augur well with the desire to translate "didactic education" to "clinical practice performance" (Hawks, 2014, p. 264). The twenty-first century learner or millennial exhibits multi-tasking behavior and is purported to have a shorter attention span, when compared with previous generations (McLean, Attardi, Faden, \& Goldszmidt, 2016). I wish to share a few pointers to help modern learners and faculty engage with, apply and enjoy teaching and learning experiences. 


\section{Research Background}

Richard Horton, Editor-in-Chief of The Lancet in 2010 lamented, "Medical education is fundamentally conservative, indoctrinating new generations into the failed ways of the old. For too long, we have hugged the shore of safe and acceptable tradition" (p. 1972). Large-group lectures continue to be the norm in medical, nursing, pharmacy, and allied health education (Pierce \& Fox, 2012). It would seem absurd that such courses, being incredibly content-heavy, are still delivered in a face-to-face didactic manner. With the recent advancements in technology and its application to education, formal and informal learning have progressed phenomenally by way of e-learning, online learning, podcasts, blogs, videos, tele-health, social media (Facebook, Twitter), simulation, gaming, virtual and augmented reality. The degree of interactivity and authenticity offered by some of these platforms for learning can be quite surprising, compared to conventional 'detached' modes of learning. Moreover, previously sedentary modes of learning with a desktop or laptop computer have been revolutionized by portable technology: mobile phones and handheld devices are ubiquitous.

Flipping the medical lesson occurs when didactic content (prerecorded lectures, screencasts, readings, videos, assessment for learning quizzes - also known as online learning objects) is made available outside of the classroom or traditional learning space, thus freeing actual in-class time for active learning through case studies, inquiry-based laboratories, handling of models, role-playing or basic surgical skills like suturing. Examples from radiology clerkships, pharmacy, nursing, health science, emergency medicine, and pediatric medicine illustrate students appreciate having unlimited access to content-rich learning objects, thus feeling more well prepared and confident (Belfi, Bartolotta, Giambrone, Davi, \& Min, 2015; Hanson, 2016; Lew, 2016; Mortensen \& Nicholson, 2015; Pierce \& Fox, 2012; Rotellar, 2016; Simpson \& Richards, 2015).

We move away from a teacher-led instruction model where learners have to cope with note-taking, assimilation, and processing of information, sense-making for knowledge building all at the same time. Providing learners with content beforehand allows them to go through all those processes and reflect on the learning in their own space and time. In a recent study conducted in the Netherlands on how medical students prepare for flipped classrooms, they were given access to online lectures, text selections, relevant scientific publications, e-books, formative quizzes (to test their understanding as they progress in their web-learning), and virtual case studies (Bouwmeester, de Kleijn, ten Cate, van Rijen, \& Westerveld, 2016). The popularity of online lectures and text selections outstripped the other modalities for learning, indicating that student preparation using these basic study materials was not only preferred, but deemed "sufficient for active in-class participation" (p. 53). Medical students are very selective in their pre-class preparation time due to the limited time for study in basic science and clinical courses. Notwithstanding the evidence, this study tells us nothing of medical students' use of non-online study 
materials such as physical books and journals, as well as online lectures from other sources, to prepare for their face-to-face lessons.

The flipped instructional model is particularly valuable in healthcare where clinical understanding learnt asynchronously is enriched by 'doing' or practice. In a clinical environment, there are opportunities for pure biomedical science knowledge to be translated into clinical reasoning and management of care. Furthermore, for skills in communication, patient history taking, physical examination, and procedural dexterity, theory studied beforehand can be applied in the classroom or in bedside teachings. Situational learning is enhanced by a flipped instruction approach (Lave \& Wenger, 1991). True to adult learning principles under the aegis of Social Constructivist theory, the learner is autonomous, self-paced, collaborative, and has access to instructional material on demand. All three medical schools in Singapore, at the National University of Singapore (NUS), the Nanyang Technological University (NTU), and Duke-NUS have adopted the use of technology to enhance pedagogy and assessment. The classroom environments boast equipment and devices that allow for state-of-the-art learning-Anatomage Table for 3-D anatomy visualization and sophisticated surgery practice simulators with virtual reality goggles, for example.

As with all disruptive paradigms, the learning curve can be steep for healthcare students and faculty who embrace the flipped model. It is not uncommon to encounter real and lasting challenges with regards to the use and management of technology (Moraros, Islam, Yu, Banow, \& Schindelka, 2015). Time management is also of concern as learners (most of whom already being in full-time employment in the healthcare industry) have to discipline themselves to be knowledgeable about the subject matter and well prepared before going to class. It is also an uphill struggle for medical faculty members to apportion valuable time to convert their once considered perfectly valid lecture-style teachings to the flipped model. Both students and faculty need to display learning agility and adaptive behaviors for optimal results. Motivation in students or graduates for non-instructor led lecture sessions varies. Reactions to such 'violent' pedagogical changes also vary. For undergraduate medical education, a comprehensive scoping review of 26 articles on the use of the flipped classroom reveals that it is inconclusive to state that the flipped model is more effective than traditional pedagogy (Ramnanan \& Pound, 2017). They posit that the lack of standardization of assessment tools or methods (academic examinations) may be a possible explanation for this. Regardless, "lifelong self-directed learning skills are perceived by medical students to be enhanced" by the flipped classroom (p. 63).

Another factor to consider regarding the uptake of the flipped classroom model is cultural differences. Chinese medical students, in a clinical diagnostics module were taught how to interpret an electrocardiogram in a flipped model. Accustomed to traditional lecture-style teaching, these students lacked confidence in their ability to do autonomous learning and peer coaching (Rui et al., 2017). Resistance to cultural adjustments was explained thus - "respecting the authority of the lecturer leads to distrust in a new learning model that lacks systematic explanation and instead relies on student-teacher interactions" (n. p.). Despite students finding the 
adaptation to novel modes of delivery and learning habits onerous, they paradoxically obtained higher scores in the knowledge acquisition test (compared to the group of students who did not receive the traditional method of training). Similarly, teachers found the flipped model exercise more onerous in terms of time and energy, yet they also reported that it had greater learning effects.

Besides cultural preferences, countries - and even individual organizationshave varying availability levels of infrastructure, resources, access, and training for the use of technology. Not all are able to operate at levels of ease in order to harness technology for teaching. In the literature search conducted on the use of flipped classroom in medical education, almost all studies found were from institutions in North America (the US and Canada), with a few from Australia, New Zealand, China, Taiwan, Israel, India, the Netherlands, and Germany. One could suppose that due to the absence of positive results yielded from experimentation with the flipped model, there are fewer publications from countries that are not listed above. Another plausible argument is that unless the institution or country has reliable access to technology and adequate technological support services, it is unlikely that teachers in healthcare are going to attempt the flipped model.

Done well, the flipped model is able to address the intricacies of specialized learning, for example, in the fields of Emergency Medicine, Nursing, Public Health and epidemiology, and physiotherapy. Tainter and his colleagues (2017) devised an intensive care unit (ICU) education curriculum and its evaluation using the flipped classroom paradigm for teaching the foundation of critical care knowledge. Residents from different specialty backgrounds such as surgery, anesthesiology, and internal medicine came together to learn about point-of-care echocardiography, part of their surgical ICU training. Video files were made accessible to learners via a Dropbox link. In hospitals that enforce strict cyber security practice, Dropbox may not be an option; hosting videos and content on the intranet could be a solution to access problems. Knowledge acquisition was tested with multiple choice questions pre- and post-test. Positive results for active learning and higher order cognitive work were reported. Learners also declared that they felt more confident with the content area and being able to use the new knowledge and skills. More positive examples of flipped classroom interventions in graduate medical education include teaching Medical Leadership to faculty of Health, Medicine, and Life Sciences at Maastricht University (Lucardie, Berkenbosch, van den Berg, \& Busari, 2017), and the use of RadCasts, RadTorials and RadGames interactive online teaching tools in a radiology clerkship (Belfi et al., 2015).

The flipped model is an inverted classroom concept, with peer learning, immediate feedback from instructor/facilitator and colleagues/peers for a metacognitive approach to instruction. Unhugging "the shore of safe and acceptable tradition" will take resources and courage (Horton, 2010, p. 1972) - as such, I would like to offer some guidance in making that transition. 


\section{Flipped Instruction in Medical Education: Best Practices}

Time, effort, money, flexibility of mindset, and motivation are recurring obstacles in effecting change of any sort. Influencing busy clinicians and residents or students to change their way of teaching and learning is not easy. But first, we have to create a safe and supportive blended learning environment; only then can we try our best to make it a win-win situation for learners and teachers.

\section{The environments}

I employ the plural form 'environments' as teaching and learning occur in a physical environment as well as a virtual environment. These are some aspects of medical environments that medical educators should consider:

- Various graduate medical education environments such as the intensive care unit and emergency medicine are highly complex learning environments (Tainter et al., 2017; Tan, Brainard, \& Larkin, 2015). Teaching in these environments requires greater clinical relevance, preferably in small groups with learning that is case-based, skill-based, and problem-solving through application of new knowledge.

- Serious games can be utilized for online learning, to enhance patient safety skills and overall quality improvement. In the case of Nursing, a highly process-driven profession, memorization of 'steps' in procedures can be acquired through online learning, followed by face-to-face sessions that are useful for guided practice. In Singapore, nursing students who have completed online learning engage in virtual activities that reinforce learning. Serious games are an example of these activities - in particular, one known as Serious Nurse.

- Proper IT support is necessary. Learning Management Systems (LMS) can be difficult for both course designers and learners to use and navigate. Assistance from a dedicated instructional designer would be very valuable. New software, authoring tools, and apps are not always instinctive for the course creator.

- Although it may seem insignificant, do try and identify the environmental and cultural forces that affect the Millennial Learner (Roberts, Newman, \& Schwartzstein, 2012). Awareness of the potential tensions and influences affecting all stakeholders allows for better responses to their needs and desires.

- Lastly, formal accreditation standards applied to schools' and hospitals' curricula, teaching, and assessment will help to steer and monitor quality assurance of education in learning environments. 


\section{The learner}

For concepts that are not too abstract for the medical student, the flipped model is helpful. Concepts in cardiovascular, respiratory, and renal physiology qualify for such pedagogy (Tune, Sturek, \& Basile, 2013). Evidence from an ophthalmology clerkship teaching comparing traditional didactic lectures and the flipped model indicate that student final exam scores were not significantly different (Lin et al., 2017). Not surprisingly, however, researchers found that students who engaged in the flipped model better developed skills in problem-solving, creative thinking and team working. Below are some tips for medical educators wishing to implement the flipped model:

- Evaluate learners' comfort levels in the use of technology for learning (Moraros et al., 2015).

- Ensure that they all have free (or reasonably priced) access to the Internet, hardware, and software.

- Make the concept of the flipped classroom clear: Content learning is done online before attending class for application, analysis, evaluation, and synthesis of knowledge (Bloom, 1956). Students must complete the quizzes whether they are assessments for or of learning. It is good to incorporate open channels of communication between student and tutor: either online forum or chat group, depending on the size of the class. When students are stuck, face difficulties, or need some quick answers while working on the online course materials, it is reassuring to be able to reach the course facilitator or their peers to get some help.

- Remind learners that skipping face-to-face interactions or clinical rounds in the wards, thinking that they have already 'learnt' online asynchronously is not acceptable. It is a common misconception of students who are not familiar with the flipped model (EDUCAUSE, 2012). In one undergraduate nursing student experiment to increase understanding of drug science and its application to clinical practice, students who chose not to come to class for face-to-face lectures were not penalized (Hanson, 2016). They were provided full access to recorded lectures.

- Use pedagogical strategies such as quizzes, peer discussions, critical analysis of case studies during in-class sessions to enhance high-level thinking and engagement. Both an integrative review (Njie-Carr et al., 2017) and a systematic review (Betihavas, Bridgman, Kornhaber, \& Cross, 2016) recommend cultural and pedagogical changes in nursing education to enable evidence-based teaching strategies to guide the conception and implementation of the flipped classroom approach.

\section{The facilitator}

I choose the term facilitator over teacher to emphasize the role of the person guiding learners in face-to-face sessions where active learning takes place through activities and discussions for deeper and more meaningful learning. 
Decreasing teaching time and increasing course content load (as more and more is known about the pathophysiology of diseases, genetics, drugs and their long-term side effects, treatment technologies, etc.) have pushed medical educators to adopt the flipped classroom. The following are important considerations for the medical education facilitator:

- A timely distribution (for instance, a week ahead) of videos, reading materials, etc., is ideal so that learners can prepare for quizzes and in-class activities.

- Short, bite-sized sequences or chunking are most effective, especially for millennials or the new generation of learners, as microlearning is ideal for those using their smartphones or tablets to access course material while 'on the go'. In her blog on bite-sized learning, Karla Gutierrez made eight recommendations regarding lesson material: one idea, engage, to-the-point, short, high contextuality, user-friendly, customized to learners' needs (Shift Disruptive Learning, 2015, Nov 26, n.p.). Similarly, it is best to keep videos to ten minutes or less. In a Lancet article, medical students' optimal concentration during lectures was found to be between ten to twenty minutes (Stuart \& Rutherford, 1978).

- Personalizing teaching is of prime importance. Different student levels necessitate changes to the lesson material - if a video lecture has been created for a 'Falls Prevention' course aimed at Nurses, Allied Health professionals, and Doctors, it is not advisable to reuse it without adaptation for students who have had less clinical exposure. To improve learning outcomes, many educational institutions have invested in creating user-specific material. For instance, faculty at UNC Eshelman School of Pharmacy created 25 user-specific integrated learning accelerator modules (iLAM) using Echo 360 Classroom Capture, which was hosted on a web-based Learning Management System (LMS - Sakai) that students could access at will (McLaughlin et al., 2014).

- However, not all teaching resources have to be made from scratch, especially with competing service demands on clinicians. Wherever appropriate, one can opt for Open Educational Resources. Here are a few medicine-specific suggestions for ready-made online lectures and open educational video sites: MedTube for surgical procedures, Institute for Healthcare Improvement, LinksMedicus, and Free Open Access Meducation (Tolks et al., 2016).

Several teaching hospitals collaborate and freely share videos either on their website or on YouTube or Vimeo. As long as they meet the learning objectives and are fit for purpose, these resources can be curated, used, and shared. Remember to cite sources and credit the authors.

- Finally, for the face-to-face sessions, incorporate problem-solving exercises to further engage with learners, give helpful and timely feedback, and foster reflection for deep learning. 


\section{Teaching Hospital Residents in Singapore via Flipping}

After meeting with counterparts at our partner teaching hospital in 2014, we decided to explore switching from solely lecture-style teaching to the FC model. The pilot project had to be small and achievable - 30 Postgraduate Year 1 (PGY1) Medicine and Surgery residents participated in a module on Ethics and the Law/Communications. The topics included Informed Consent, the Mental Capacity Act (MCA) and Lasting Power of Attorney (LPA), Basics of Advanced Care Planning, Privacy and Confidentiality, Personal Data Protection Act (PDPA), Disclosure, Service Recovery, The Essentials of Breaking Bad News. The face-to-face sessions were scheduled fortnightly for about 10 weeks. Textbook-style, we planned, implemented, enacted, and evaluated our pilot flipped classroom project (Moffett, 2015; Sharma, Lau, Doherty, \& Harbutt, 2015).

Videos of not more than ten minutes were prepared using a voice commentary of Powerpoint slides using Office Mix, a free video creating software that is available to Office 365 (Microsoft) subscribers. Case-based scenarios were written for each topic, as well as quizzes. We faced several technological and cost challenges. At the time, a decision was made by our IT department to abandon the LMS in existence in favor of another integrated LMS. Users had to pay a fee to have login access, even though, they would not be needing the LMS access after ten weeks. In the face of these constraints, we chose to collate the videos and pdf documents in an E-book on Canva (free graphic design software, canva.com) and to upload it to an app called Issuu (issuu.com), a free digital publishing platform that is both attractive and very easy to use on handheld devices (Traxler, 2009).

The mode of access to the online module was communicated to the PGY1s in an email. They were encouraged to review and learn before coming to class. We did not feel that learning had to be linear. All the chapters were made available and they could navigate the entire E-book. Subjects were prioritized into 'must know', 'good to know', and optional materials. Two optional resources were podcasts that are part of the BBC Reith Lectures featuring Dr. Atul Gawande as the eminent guest speaker broaching the topics Why do doctors fail and The problem of hubris.

The same format was adhered to for each chapter-learning objectives, main concepts, facts, case studies, and further points for discussion. In the classroom activities, decision-making skills and reflection were greatly solicited. Ethics and the Law topics were an eye-opener to many - although laws are meant to be 'black' or 'white', there was much room for debate and for the preservation of human dignity when it came to applying the laws to the letter. Teamwork in small groups was encouraged and previously timid participants began coming out of their shell, affirming their viewpoints and objections.

Feedback was sought at the end of every lesson. Initially, the PGY1s found it tough to discipline themselves to 'study' before showing up for class. When they realized how much more quality learning they got out of class time when they were prepared, they gradually changed their approach. There were no issues of access, mostly done from their mobile phones. Sessions were held from 1 to $3 \mathrm{pm}$ and 
lunch was provided to our busy residents in training. They appreciated the attention to detail as they are often hungry, tired, and stressed. The E-book was found to be aesthetically pleasing and enjoyable as a didactic interface The PGY1s also expressed an experience of self-efficacy (Kissinger, 2013). I am cognizant of my own bias; however, I sincerely feel that we (faculty and administrative staff) did our utmost to build privileged intergenerational relations with our Generation $Y$ learners (Gillespie, 2016) with positive outcomes for both parties.

\section{Implications and Conclusion}

A common critique of the flipped model is it only measures effectiveness by an improvement in grades, when compared to traditional pedagogy. A migration from grade-centric evaluation to evaluating the quality of the process and experience of the FC model that reflect student-focused approaches will be a useful complementary measure. Jensen, Kummer, and Godoy's (2015) findings to the effectiveness of flipped approach over a non-flipped approach are inconclusive-if active learning is integrated into both approaches, the flipping methodology bears no significance.

Securing buy-in from participants is a challenge when working with healthcare professionals. The demands on their time, skills, and additional work have to be negotiated with care, sincerity, and diplomacy. Added stressors of being judged by their peers in a completely new teaching modality may be a setback for less adaptable medical faculty members. DeCoste-Lopez (2015) at Stanford Medical School turns the argument on its head by inviting faculty to work hard at it and to be accepting of peer critique. She lauds the value of peer pressure. In the domain of research, accountability and credibility are of prime importance. The same should apply to the domain of teaching. She describes her experience of working on microbiology and immunology curricula to be delivered using the flipped model. It was a collaborative endeavor involving four other medical schools - a conscious choice to embrace peer judgment proved to be beneficial to all. Her conclusion is that the flipped model helps to incentivize faculty to prioritize teaching.

We pride ourselves in being able to manage healthcare student expectations, but do we really? The sheer volume of learning material, demanding work commitments or training schedules and family responsibilities are a recurring problem (Tan, Brainard, \& Larkin, 2015). Flipped learning should be designed with sufficient recall competencies without overtaxing the memory. Less 'must know' content may be more; facts can rapidly be obtained when required. Sharpening clinical reasoning skills, thinking on their feet, and improving confidence in exercising judgment should be prioritized.

Videos, podcasts, interactive games, and quizzes are the most common resources available for flipped learning in Singapore. Faculty are offered 'train the trainer' modules in learning technology for teaching. These skills are intuitive for some; for others were probably not early adopters of technology, the learning curve may 
prove to be a bit steep. Best practices in these circumstances would have to be adaptable to faculty's rate of acceptance for and the ability to change. With sustainable change in habits to embrace technology and to use it to teachers' and learners' advantage, the flipped classroom model will stand the test of time.

Learners take control of their own learning, playing an active and proactive role in their education (Bransford, Brown, \& Cocking, 2000). The traditional model of instruction where learners are passive receptacles of information is transformed into empowering learners to participate, share, exchange, and co-construct knowledge. Dr. Eric Topol (2012) believes that consumers of healthcare are "fully capable of leading the movement and contributing to medicine's creative destruction" (p. 195). He refers to the agility or 'plasticity' of doctors, and how their digital literacy can further advance the convergence of technologies in genomics, imaging, and sensors for novel solutions. Likewise, digital native healthcare learners, or 'medical digerati' (to borrow Topol's term) must lead the disruptive change in education.

\section{References}

Belfi, L. M., Bartolotta, R. J., Giambrone, A. E., Davi, C., \& Min, R. J. (2015). "Flipping” the introductory clerkship in radiology: Impact on medical student performance and perceptions. Academic Radiology, 22, 794-801.

Berwick, D., \& Finkelstein, J. (2010). Preparing medical students for the continual improvement of health and health care: Abraham Flexner and the new "public interest." Academic Medicine, 85(9 suppl), S56-S65.

Betihavas, V., Bridgman, H., Kornhaber, R., \& Cross, M. (2016). The evidence for 'flipping out': A systematic review of the flipped classroom in nursing education. Nurse Education Today, 38, $15-21$.

Bloom, B. (1956). Brame, C. (n.d.). Flipping the classroom. Center for Teaching. Retrieved online at http://cft.vanderbilt.edu/guides-sub-pages/flippingthe-classroom/.

Bouwmeester, R. A. M., de Kleijn, R. A. M., ten Cate, O. T. J., van Rijen, H. V. M., \& Westerveld, H. E. (2016). How do medical students prepare for flipped classrooms? Medical Science Educator, 26, 53. https://doi.org/10.1007/s40670-015-0184-9.

Bransford, J., Brown, A., \& Cocking, R. (2000). How people learn: Brain, mind, experience, and school. Washington, D.C: National Academy Press.

DeCoste-Lopez, J. (2015). Vantage point: How the flipped classroom boosts faculty interest in teaching. Retrieved online at http://med.stanford.edu/news/all-news/2015/05/how-the-flippedclassroom-boosts-faculty-interest-in-teaching.html.

EDUCAUSE. (2012). 7 things you should know about flipped classrooms. Retrieved online at http://www.educause.edu/library/resources/7-things-you-should-know-about-flippedclassrooms.

Gillespie, V. (2016). Using the flipped classroom to bridge the gap to generation Y. Ochsner Journal, 16(1), 32-36.

Hanson, J. (2016). Surveying the experiences and perceptions of undergraduate nursing students of a flipped classroom approach to increase understanding of drug science and its application to clinical practice. Nurse Education in Practice, 16, 79-85.

Hawks, S. (2014). The flipped classroom: Now or never? AANA Journal, 8(4), 264-269.

Horton, R. (2010). Offline: If I were a rich man. Lancet, 376(9756), 1972. https://doi.org/10.1016/ S0140-6736(10)62238-6. 
Jensen, J., Kummer, T., \& d M Godoy, P. (2015). Improvements from a flipped classroom may simply be the fruits of active learning. CBE Life Science Education, 14(1). https://doi.org/10. 1187/cbe.14-08-0129.

Kissinger, J. (2013). The social and mobile learning experiences of students using mobile E-books. Journal of Asynchronous Learning Networks, 17(1), 153-169.

Lave, J., \& Wenger, E. (1991). Situated learning: Legitimate peripheral participation. Cambridge: Cambridge University Press.

Lew, E. (2016). Creating a contemporary clerkship curriculum: the flipped classroom model in emergency medicine. International Journal of Emergency Medicine, 9(25).

Lin, Y., Zhu, Y., Chen, C., Wang, W., Chen, T., Li, T., ... Liu, Y. (2017). Facing the challenges in ophthalmology clerkship teaching: Is flipped classroom the answer? PLoS One, 12(4).

Lucardie, A. T., Berkenbosch, L., van den Berg, J., \& Busari, J. O. (2017). Flipping the classroom to teach Millennial residents medical leadership: A proof of concept. Advances in Medical Education and Practice, 8, 57-61. http://doi.org.liverpool.idm.oclc.org/10.2147/AMEP. S123215.

McLaughlin, J., Roth, M., Glatt, D., Gharkholonarehe, N., Davidson, C. A., Griffin, L. M., ... Mumper, R. J. (2014). The flipped classroom: a course redesign to foster learning and engagement in a health professions school. Academic Medicine, 89(2), 236-243.

McLean, S., Attardi, S., Faden, L., \& Goldszmidt, M. (2016). Flipped classrooms and student learning: Not just surface gains. Advances in Physiology Education, 40(1), 47-55.

Moffett, J. (2015). Twelve tips for "flipping" the classroom. Medical Teacher, 37(4), 331-336.

Moraros, J., Islam, A., Yu, S., Banow, R., \& Schindelka, B. (2015). Flipping for success: Evaluating the effectiveness of a novel teaching approach in a graduate level setting. $B M C$ Medical Education, 15(27).

Mortensen, C. J., \& Nicholson, A. M. (2015). The flipped classroom stimulates greater learning and is a modern 21 st century approach to teaching today's undergraduates. Journal of Animal Science, 93(7), 3722-3731.

Njie-Carr, V. P., Ludeman, E., Lee, M. C., Dordunoo, D., Trocky, N. M., \& Jenkins, L. S. (2017). An integrative review of flipped classroom teaching models in nursing education. Journal of Professional Nursing, 33(2), 133-144.

Pierce, R., \& Fox, J. (2012). Vodcasts and active-learning exercises in a 'flipped classroom' model of a renal pharmacotherapy module. American Journal of Pharmaceutical Education, 76, 1-5.

Prober, C., \& Khan, S. (2013). Medical education reimagined. A call to action. Academic Medicine, 88(10), 1407-1410.

Ramnanan, C. J., \& Pound, L. D. (2017). Advances in medical education and practice: Student perceptions of the flipped classroom. Advances in Medical Education and Practice, 8, 63-73.

Roberts, D., Newman, L., \& Schwartzstein. R. (2012). Twelve tips for facilitating Millennials' learning. Medical Teacher, Early Online, 1-5. Retrieved online at http://www.xyoaa.org/sites/ all/modules/ckeditor/ckfinder/ckfinder/userfiles/files/education_materials/Millennials'\% 20Learning\%20Tips.pdf.

Rotellar, C. (2016). Research, perspectives, and recommendations on implementing the flipped classroom. American Journal of Pharmaceutical Education, 80(2), 1-9.

Rui, Z., Lian-rui, X., Rong-zheng, Y., Jing, Z., Xue-hong, W., \& Chuan, Z. (2017). Friend or foe? Flipped classroom for undergraduate electrocardiogram learning: A randomized controlled study. BMC Medical Education, 17, 53. https://doi.org/10.1186/s12909-017-0881-8.

Ruiz, J., Mintzer, M., \& Leipzig, R. (2006). The impact of E-learning in medical education. Academic Medicine, 81(3), 207-212.

Sharma, N., Lau, C. S., Doherty, I., \& Harbutt, D. (2015). How we flipped the medical classroom. Medical Teacher, 37(4), 327-330.

Shift Disruptive Learning. (2015). Think small: 8 commandments of bite-sized learning. E-learning. Blog by Karla Gutierrez posted on Nov 26, 2015. Retrieved online at http:// info.shiftelearning.com/blog/commandments-of-bite-sized-learning. 
Simpson, V., \& Richards, E. (2015). Flipping the classroom to teach population health: Increasing the relevance. Nursing Education in Practice, 15, 162-167.

Skinner, B. (1974). About behaviorism. New York: Knopf.

Stuart, J., \& Rutherford, R. J. (1978). Medical student concentration during lectures. Lancet, 2 (8008), 514-516.

Tainter, C., Wong, N., Cudemus-Deseda, G., \& Bittner, E. (2017). The "flipped classroom" model for teaching in the intensive care unit. Journal of Intensive Care Medicine, 32(3), 187-196.

Tan, E., Brainard, A., \& Larkin, G. (2015). Acceptability of the flipped classroom approach for in-house teaching in emergency medicine. Emergency Medicine Australasia, 27, 453-459.

Tolks, D., Schafer, C., Raupach, T., Kruse, L., Sarikas, A., Gerhardt-Szép, S., ... Sostmann, K. (2016, May 17). An introduction to the inverted/flipped classroom model in education and advanced training in medicine and in the healthcare professions. GMS Journal for Medical Education, 33(3), Doc46. https://doi.org/10.3205/zma001045.

Topol, E. (2012). The creative disruption of medicine: How the digital revolution will create better healthcare. New York: Basic Books.

Traxler, J. (2009). Learning in a mobile age. International Journal of Mobile and Blended Learning, 1(1), 132.

Tune, J. D., Sturek, M., \& Basile, D. P. (2013). Flipped classroom model improves graduate student performance in cardiovascular, respiratory, and renal physiology. Advances in Physiology Education, 37(4), 316. 